\title{
A Transfer for PCI versus Conservative Treatment at a Late Electrocardiographic Stage of Myocardial Infarction on Admission: Long-Term Outcomes
}

Egle Kalinauskiene*, Laura Urbonaite, Dalia Gerviene and Albinas Naudziunas

Department of Internal Medicine, Medical Academy, Lithuanian University of Health Sciences

"Corresponding author: Egle Kalinauskiene, Josvainiu 2, Department of Internal Medicine, Medical Academy, Lithuanian University of Health Sciences, Kaunas 47144, Lithuania, Tel: +370 37 306093; Fax: +370 37 306093; E-mail: eglekalin@yahoo.com

Received date: April 23, 2015; Accepted date: May 15, 2015; Published date: May 18, 2015

Copyright: ( 2015 Kalinauskiene E. This is an open-access article distributed under the terms of the Creative Commons Attribution License, which permits unrestricted use, distribution, and reproduction in any medium, provided the original author and source are credited.

\begin{abstract}
Background: Primary percutaneous coronary intervention (PCI) is the preferred reperfusion strategy in acute STelevation myocardial infarction (MI), but is unclear what electrocardiographic (ECG) signs on admission show that it is too late to transfer the patients to a PCl-capable hospital. Therefore, we performed this exploratory study.

Methods: A prospective cohort study enrolling 42 patients with the chosen signs of a late ECG stage of MI on admission was performed. Long-term outcomes were compared in 15 patients treated conservatively and 12 patients transferred to a $\mathrm{PCl}$-capable hospital who underwent $\mathrm{PCl}$. The new ischemic events, deaths, changes in the ECG QRS score, echocardiographic ejection fraction, and index of impaired myocardial contraction were assessed after 1.5 years.

Results: No significant differences were found in the groups, except for impaired myocardial contraction, which improved in the $\mathrm{PCl}$ group (a score of $1.83 \pm 0.98$ vs. $0.78 \pm 0.44, \mathrm{P}=0.04$ ), but this group was significantly younger $(65.3 \pm 13.86$ vs. $80.1 \pm 6.17, P=0.006)$.

Conclusions: There were no clear advantages of the transfer for PCl over conservative treatment at this ECG stage of $\mathrm{Ml}$ on admission, except the improvement of impaired myocardial contraction. That is a hypothesis for later confirmation in larger age standardized studies, because in our study many patients were lost due to specific patients arriving to a non-PCl-capable hospital and the patients transferred for $\mathrm{PCl}$ were significantly younger. We hope this study will help plan further researches.
\end{abstract}

Keywords: Myocardial infarction; T-wave inversion; non-PCIcapable hospital; Long-term outcomes

\section{Introduction}

Reperfusion therapy gives undoubted benefit during the acute phase of a ST-elevation myocardial infarction, but there is a lack of information on the choice of different treatment strategies at a late electrocardiographic (ECG) stage of myocardial infarction (MI) on admission. The clinician's choice whether to transfer the patients to a PCI-capable hospital for performing the percutaneous coronary intervention (PCI) or to choose conservative treatment in a non-PCIcapable hospital refers to ischemic time [1]. While the duration of clinical symptoms is a subjective criterion, definite electrocardiographic patterns are more reliable in estimating the duration of ischemia. Pathologic Q wave presentation is associated with more frequent major adverse cardiovascular events [2]. Moreover, T-wave inversion may be a predictor of long-term outcomes. The DANAMI-2 trial reported that fibrinolytic therapy resulted in similar long-term outcomes as primary PCI when T-wave inversion was present [3]. Primary PCI and especially fibrinolytic therapy are recommended only in early cases of ST-elevation MI [1]. It is unclear what ECG signs on admission show that it is too late to transfer the patients to a PCI-capable hospital. So, the aim of the present exploratory study was to compare the long-term outcomes of the patients treated conservatively (without fibrinolytic therapy) in a
non-PCI-capable hospital versus the patients transferred for primary PCI when the chosen signs of a late ECG stage of MI on admission were present.

\section{Material and Methods}

This prospective cohort study was carried out at the non-PCIcapable Kaunas Clinical Hospital (no team of interventional cardiologists) and the PCI-capable Hospital of Lithuanian University of Health Sciences (having a team of interventional cardiologists). Patients with MI, who presented to the Admitting Department of Kaunas Clinical Hospital between January 2010 and June 2011, were included in the study. Patients were eligible for inclusion if they agreed to participate in this research study and had the first Q-wave MI on admission diagnosed in the presence of chest pain lasting for $\geq 30$ minutes, ST segment in the isoelectric line or elevated $\leq 1.0 \mathrm{~mm}$ (at the J point) in $\geq 2$ contiguous leads on the 12-lead ECG, pathological Q wave (a description by Wagner, et al.) with $\mathrm{T}$-wave inversion $(\geq 1.0$ $\mathrm{mm}$ below the isoelectric line with initial positive deflection or without initial positive deflection), and confirmed by the troponin test [4]. Patients with bundle branch block or ventricular pacemakers were excluded. The study population was divided into 2 groups according to the treatment strategy: those who were conservatively treated and those who were subjected to primary PCI by the judgment of an attending cardiologist based on presenting characteristics and the duration of symptoms as recommended in standard guidelines [5]. If 
Citation: Kalinauskiene E, Urbonaite L, Gerviene D, Naudziunas A (2015) A Transfer for PCl versus Conservative Treatment at a Late Electrocardiographic Stage of Myocardial Infarction on Admission: Long-Term Outcomes. J Cardiovasc Dis Diagn 3: 198. doi: $10.4172 / 2329-9517.1000198$

Page 2 of 4

the interventional strategy was chosen, the patients were transferred to the Hospital of Lithuanian University of Health Sciences. The data collected during hospitalization and at approximately 1.5 years $(19 \pm$ 0.75 months) after discharge were compared in both groups. Both patients' groups received the same initial medications, and no fibrinolytic therapy was administered. All PCI patients and 13 conservatively managed patients $(86.67 \%)$ were placed on dual anti platelets therapy. One patient did not receive this therapy due to thrombocytopenia and one due to intestinal bleeding. All patients received B blockers, ACE inhibitors and statins, but statins less often in conservative treatment group (4 patients $(26.7 \%)$ vs. all in PCI group, $\mathrm{p}=0.031$ ). The new ischemic events, deaths, changes in the ECG QRS score, echocardiographic ejection fraction, and index of impaired myocardial contraction were assessed after 1.5 years.

On admission and after 1.5 years, 12-lead ECGs were recorded and analyzed. In order to estimate the size of MI, the Selvester QRS scoring system, simplified and modified by Wagner et al. [4], was applied. Simplified Selvester QRS score (29-point) was measured manually by two independent persons for each electrocardiogram. The observers were experienced and blinded to the other results. For the evaluation of the left ventricular function, transthoracic echocardiography was performed by single observer. The observer was experienced and blinded to the other results. Regional myocardial contraction was graded on a 0-4-point scale as follows: 0- normal contraction; 1hypokinesia; 2- akinesia; 3- dyskinesia; and 4- aneurism; the index of impaired myocardial contraction was calculated. For the clinical evaluation of pulmonary congestion, patients underwent lung auscultation and chest $x$-ray examination. Rales were assessed as follows: none, in $\leq 1 / 3$ of the lungs, and in $>1 / 3$ of the lungs. The findings of the $\mathrm{x}$-ray examination were assessed as follows: no signs of

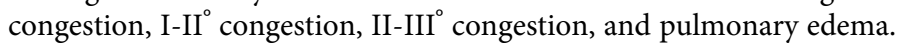
Clinical Killip class was assessed as well.

\section{Statistical analysis}

Continuous values were expressed as the mean \pm standard deviation. Statistical significance was assessed by the $\chi^{2}$ exact test for categorical variables and the Mann-Whitney $U$ exact test for numerical variables. Differences in the same groups between the admission and 1.5-year follow-up data were assessed using the Wilcoxon Rank Sum exact test. Comparisons of discrete variables were performed using the Fisher exact test. Statistical significance was accepted when the probability value was $<0.05$.

\section{Results}

A total of 42 patients were recruited to the study; however, 11 died before the treatment, and 4 were excluded due to arising confounding ECG findings. The mean age of dead before the treatment was $78.9 \pm$ $10.5 \mathrm{yr}$., 10 female (90.9\%) and 1 male (9.1\%). MI localization was anterior in 7 cases $(63.63 \%)$. Their mean troponin $\mathrm{T}$ was $0.97 \pm 0.97$ $\mathrm{g} / \mathrm{l}$. Their mean QRS score was $4.37 \pm 2.77$. Of the remaining 27 patients, 12 (44.44\%) underwent primary PCI and $15(55.56 \%)$ received conservative treatment. The mean door to balloon time was $157.83 \pm 92.63$ minutes. Nine $(75 \%)$ patients underwent successful stent placement, 3 (25\%) patients no - one did not receive it due to stenosis $<75 \%$ and 2 due to 3 -vessel disease were directed for the surgical treatment.

The baseline clinical characteristics of the patients on admission are presented in Table 1. The patients who underwent PCI were significantly younger. Both groups were matched by Killip class, extent of rales in the lungs, signs of congestion according to the chest x-ray findings, ECG MI localization, QRS score, and echocardiographic findings. The troponin $\mathrm{T}$ level was higher in the patients who underwent PCI than those receiving conservative treatment, but the difference was not statistically significant.

\begin{tabular}{|c|c|c|c|}
\hline Characteristic & $\begin{array}{l}\text { Primary } \mathrm{PCl}(\mathrm{n} \\
=12)\end{array}$ & $\begin{array}{l}\text { Conservative } \\
\text { treatment }(n=15)\end{array}$ & $P$ value \\
\hline Age, mean $\pm S D$, years & $65.3 \pm 13.86$ & $80.1 \pm 6.17$ & 0.006 \\
\hline Women, n (\%) & $4(33.3)$ & $10(66.7)$ & 0.13 \\
\hline \multicolumn{4}{|l|}{ Killip class, n (\%) } \\
\hline । & $4(33.3)$ & $4(26.7)$ & \\
\hline II & $6(50)$ & $10(66.7)$ & 0.63 \\
\hline III & $2(16.7)$ & $1(6.7)$ & \\
\hline IV & - & - & \\
\hline \multicolumn{4}{|l|}{ Rales, n (\%) } \\
\hline None & $6(50.0)$ & $6(40.0)$ & \\
\hline$\leq 1 / 3$ & $4(33.3)$ & $8(53.3)$ & 0.64 \\
\hline$>1 / 3$ & $2(16.7)$ & $1(6.7)$ & \\
\hline \multicolumn{4}{|l|}{ Chest $\mathrm{x}$-ray findings, $\mathrm{n}(\%)$} \\
\hline No signs of congestion & $6(50.0)$ & $6(40.0)$ & \\
\hline$|-1|^{\circ}$ congestion & $4(33.3)$ & $8(53.3)$ & 0.64 \\
\hline III-IV ${ }^{\circ}$ congestion & $2(16.7)$ & $1(6.7)$ & \\
\hline Pulmonary edema & - & - & \\
\hline \multicolumn{4}{|l|}{ MI localization, n (\%) } \\
\hline Anterior & $5(41.7)$ & $8(53.3)$ & \\
\hline Inferior & $7(58.3)$ & $7(46.7)$ & 0.7 \\
\hline \multicolumn{4}{|l|}{$\begin{array}{l}\text { Troponin level, mean } \pm \mathrm{SD} \text {, } \\
\mathrm{g} / \mathrm{L}\end{array}$} \\
\hline $\mathrm{T}$ & $2.22 \pm 3.34$ & $0.59 \pm 0.77$ & 0.57 \\
\hline I & $10.46 \pm 20.32$ & - & - \\
\hline \multicolumn{4}{|l|}{$\begin{array}{l}\text { Electrocardiographic } \\
\text { findings }\end{array}$} \\
\hline $\begin{array}{l}\text { QRS, mean } \pm S D \text {, score } \\
\text { (modified) }\end{array}$ & $3.67 \pm 1.97$ & $3.6 \pm 3.02$ & 0.68 \\
\hline \multicolumn{4}{|l|}{ Echocardiographic findings } \\
\hline $\mathrm{IMC}$, mean $\pm \mathrm{SD}$, score & $1.86 \pm 0.9$ & $1.18 \pm 0.6$ & 0.15 \\
\hline $\mathrm{EF}$, mean $\pm \mathrm{SD}, \%$ & $41.67 \pm 9.75$ & $43.93 \pm 9.78$ & 0.67 \\
\hline $\begin{array}{l}\text { Follow-up duration, mean } \pm \\
\text { SD, months }\end{array}$ & $20.23 \pm 3.33$ & $18.6 \pm 1.13$ & 0.24 \\
\hline
\end{tabular}

Table 1: The baseline characteristics of the study population. 
Citation: Kalinauskiene E, Urbonaite L, Gerviene D, Naudziunas A (2015) A Transfer for PCl versus Conservative Treatment at a Late Electrocardiographic Stage of Myocardial Infarction on Admission: Long-Term Outcomes. J Cardiovasc Dis Diagn 3: 198. doi: $10.4172 / 2329-9517.1000198$

Page 3 of 4

During the 1.5-year follow-up period, 3 patients experienced a new ischemic event and 1 patient presented with complete left-bundle branch block, all 4 patients being treated conservatively (Table 2). Moreover, death occurred in 5 patients and 7 patients were lost due to the changed contact information.
Comparison of the data recorded on admission and at the 1.5-year follow-up showed no significant differences in the QRS score and ejection fraction in both groups, but impaired myocardial contraction improved significantly in the PCI group (Table 2).

\begin{tabular}{|c|c|c|c|c|c|c|}
\hline & \multicolumn{3}{|c|}{ Primary $\mathrm{PCI}(n=12)$} & \multicolumn{2}{|c|}{ Conservative treatment $(n=15)$} & $P$ value \\
\hline New ischemic event or LBBB, $n$ & \multicolumn{3}{|l|}{ - } & \multicolumn{2}{|l|}{4} & 0.11 \\
\hline Lost (changed contact information), $n$ & \multicolumn{3}{|l|}{2} & \multicolumn{2}{|l|}{5} & 0.41 \\
\hline Dead, n (\%) & \multicolumn{3}{|l|}{$1(8.33)^{\star}$} & \multicolumn{2}{|l|}{$4(26.7)$} & 0.19 \\
\hline \multirow[t]{2}{*}{ Other, $\mathrm{n}$} & \multicolumn{3}{|l|}{9} & \multicolumn{2}{|l|}{2} & \\
\hline & Admission & Follow-up & $\mathrm{P}$ & Admission & Follow-up & $\mathrm{P}$ \\
\hline \multicolumn{7}{|l|}{ Electrocardiographic findings } \\
\hline QRS, mean \pm SD, score (modified) & $3.67 \pm 2.24$ & $3.5 \pm 2.27$ & 0.48 & $2.5 \pm 3,54$ & $4.0 \pm 2.83$ & 0.18 \\
\hline \multicolumn{7}{|l|}{ Echocardiographic findings } \\
\hline $\mathrm{IMC}$, mean $\pm \mathrm{SD}$, score & $1.83 \pm 0.98$ & $0.78 \pm 0.44$ & 0.04 & $1.0 \pm 0.0$ & $1.0 \pm 0.0$ & 1 \\
\hline $\mathrm{EF}$, mean $\pm \mathrm{SD}, \%$ & $43.3 \pm 9.35$ & $47.33 \pm 4.8$ & 0.26 & $55.0 \pm 7.07$ & $48.0 \pm 0.0$ & 0.18 \\
\hline
\end{tabular}

Table 2: Interventional versus conservative treatment long-term outcomes of evolved myocardial infarction.

\section{Discussion}

There were no clear advantages of the transfer for primary PCI over conservative treatment in a non-PCI-capable hospital at a late ECG stage of MI on admission by the data of this exploratory study: no significant differences were found in the groups, except for impaired myocardial contraction, which improved in the PCI group. However, this group was significantly younger. In addition, many patients were lost due to death before the treatment or excluded due to arising confounding ECG findings. Many patients were lost during the followup due to the changed contact information. So, future studies should be larger and age standardized. It was well known that primary PCI is the preferred reperfusion strategy in the setting of an acute STelevation MI, but was unclear if primary PCI is superior to conservative treatment at a late ECG stage of MI on admission, particularly for the transferred patients from the non-PCI-capable hospitals [6].

We evaluated the duration of MI based on the ECG findings, but not on the patient's complaints. In our opinion, the duration of MI based on the ECG findings is more reliable than on the patient's complaints, because the duration of clinical symptoms is a subjective criterion. The recent study showed that terminal T-wave inversion is a better predictor of outcomes in ST-elevation MI than the patientreported ischemic time [7].

In 1987, Klainman et al. delineated the following 4 stages of STelevation MI: stage I, ST-segment elevation $\geq 0.1 \mathrm{mV}$, a positive $\mathrm{T}$ wave, no abnormal Q wave; stage II, ST-segment elevation $\geq 0.1 \mathrm{mV}$, abnormal Q wave; stage III, the ST segment still elevated but a negative $\mathrm{T}$ wave begins to form; and IV stage, the ST segment in the isoelectric line with the negative T-wave [8]. According to these descriptions, our patients admitted to the hospital had stage III or IV MI.
According to the literature data, age is an independent prognostic factor [1]. However, despite the fact that our patients in the PCI group were significantly younger than those in the conservative treatment group, no significant differences in the parameters evaluated, except for impaired myocardial contraction, were found in the groups. Impaired myocardial contraction, corresponding to the myocardial infarction zone, significantly improved in the PCI group at the 1.5year follow-up, but ejection fraction remained the same in the groups. Our statistical sample was small. It is probable that larger samples will show a significant difference.

Many patients were lost due to the changed contact information and death, due to specific patients arriving to a non-PCI-capable hospital: much older, at the later stage of MI [9]. Our patients had a really late ECG stage of MI on admission. Maybe earlier ECG criteria indicating it is not worth transferring a patient for primary PCI could be found. We hope that with improving medical education of the society and better organization of the health care system, fewer patients will present at a late ECG stage of MI and more patients will receive primary PCI.

\section{Limitations}

Our statistical data must be taken with caution due to a small number of patients. This study was exploratory. Shown problems can help plan further researches.

\section{Conclusions}

Our exploratory study did not show clear advantages of the transfer for primary PCI over conservative treatment in a non-PCI-capable hospital at a late ECG stage of MI on admission, except the 
Citation: Kalinauskiene E, Urbonaite L, Gerviene D, Naudziunas A (2015) A Transfer for PCl versus Conservative Treatment at a Late Electrocardiographic Stage of Myocardial Infarction on Admission: Long-Term Outcomes. J Cardiovasc Dis Diagn 3: 198. doi: $10.4172 / 2329-9517.1000198$

Page 4 of 4

improvement of impaired myocardial contraction. That is a hypothesis for later confirmation in larger age standardized studies, because in our study many patients were lost due to specific patients arriving to a non-PCI-capable hospital and the patients transferred for primary PCI were significantly younger. We hope this study will help plan further researches.

\section{Acknowledgements}

None.

\section{Funding}

This research received no grant from any funding agency in the public, commercial or not-for-profit sectors.

\section{Conflict of Interest}

The authors state no conflict of interests regarding the publication of this paper.

\section{References}

1. O'Gara PT, Kushner FG, Ascheim DD, Casey DE Jr, Chung MK, et al (2013) 2013 ACCF/AHA guideline for the management of ST-elevation myocardial infarction: a report of the American College of Cardiology Foundation/American Heart Association Task Force on Practice Guidelines. Circulation 127: 362-425.

2. Kumar S, Hsieh C, Sivagangabalan G, Chan H, Ryding AD, et al. (2009) Prognostic impact of $\mathrm{Q}$ waves on presentation and ST resolution in patients with ST-elevation myocardial infarction treated with primary percutaneous coronary intervention. Am J Cardiol 104: 780-785.
3. Eskola MJ, Holmvang L, Nikus KC, Sclarovsky S, Tilsted HH, et al. (2007) The electrocardiogram window of opportunity to treat vs. the different evolving stages of ST-elevation myocardial infarction: correlation with therapeutic approach, coronary anatomy, and outcome in the DANAMI-2 trial. Eur Heart J 28:2985-2991.

4. Wagner GS, Freye CJ, Palmeri ST, Roark SF, Stack NC, et al. (1982) Evaluation of a QRS scoring system for estimating myocardial infarct size. I. Specificity and observer agreement. Circulation 65: 342-347.

5. Levine GN, Bates ER, Blankenship JC, Bailey SR, Bittl JA, et al. (2011) ACCF/AHA/SCAI Guideline for Percutaneous Coronary Intervention: A Report of the American College of Cardiology Foundation/American Heart Association Task Force on Practice Guidelines. Circulation 124: e574-651.

6. Task Force on the management of ST-segment elevation acute myocardial infarction of the European Society of Cardiology (ESC), Steg PG, James SK, Atar D, Badano LP, Blömstrom-Lundqvist C, et al. (2012) ESC Guidelines for the management of acute myocardial infarction in patients presenting with ST-segment elevation. Eur Heart J 33: 25692619.

7. Shimada YJ, Po JR, Kanei Y, Schweitzer P (2013) Prognostic impact of terminal $\mathrm{T}$ wave inversions on presentation in patients with ST-elevation myocardial infarction undergoing urgent percutaneous coronary intervention. J Electrocardiol 46: 2-7.

8. Klainman E, Sclarovsky S, Lewin RF, Topaz O, Farbstein H, et al. (1987) Natural course of electrocardiographic components and stages in the first twelve hours of acute myocardial infarction. J Electrocardiol 20: 98-109.

9. Gerviene D, Kalinauskiene E, Pauzuolyte R, Petrylaite V, Banaityte I, et al. (2014) Patients treated from acute myocardial infarction in a nonPCI-capable hospital and their in-hospital mortality in comparison with a PCI-capable hospital. Exp Clin Cardiol 20: 2336-2340. 